\title{
CARACTERIZAÇÃO FÍSICO-QUÍMICA E SENSORIAL DE BEBIDA PROBIÓTICA DE SOJA
}

\author{
MANOELA MARIN * \\ NATHALIA DE AVILA MADRUGA * \\ ROSANE DA SILVA RODRIGUES ** \\ MÍRIAN RIBEIRO GALVÃO MACHADO ***
}

\begin{abstract}
O objetivo deste trabalho foi avaliar bebida funcional à base de extrato de soja, lactossoro e fruto-oligossacarídeo (FOS), fermentada com a cultura probiótica Lactobacillus acidophilus (LA - NCFM) e saborizada com mel. Preparou-se a bebida controle (não saborizada) pela mistura de $50 \%(\mathrm{~m} / \mathrm{m})$ de extrato de soja com $50 \%(\mathrm{~m} / \mathrm{m})$ de lactossoro, adicionados de $2,5 \%(\mathrm{~m} / \mathrm{m})$ de açúcar comercial e $5 \%(\mathrm{~m} / \mathrm{m})$ de FOS. Após pasteurização $\left(85^{\circ} \mathrm{C} / 20 \mathrm{~min}\right.$ ), a bebida foi resfriada e fermentada com LA-NCFM a $42{ }^{\circ} \mathrm{C}$ até $\mathrm{pH} 4,5$. Para o preparo da bebida saborizada com mel efetuou-se o mesmo procedimento, sendo adicionados $10 \%(\mathrm{~m} / \mathrm{m})$ de mel após a fermentação. Em ambas as bebidas foram determinados, em triplicata, lipídios, proteínas, fibra bruta, acidez titulável, cinzas, sólidos totais, sólidos solúveis, $\mathrm{pH}$, extrato seco, açúcares totais, redutores e não redutores e índice de sedimentação. Determinou-se a viabilidade celular aos 0,15 e 30 dias após o término da fermentação. Avaliou-se a bebida saborizada com mel sensorialmente, por método afetivo, utilizando teste de aceitação simultaneamente à escala hedônica estruturada de 1 a 7 pontos. A bebida à base de extrato de soja, lactossoro e fruto-oligossacarídeo, fermentada com cultura probiótica e saborizada com mel apresentou parâmetros físico-químicos adequados, manteve-se de acordo com o padrão exigido pela legislação brasileira para contagem de número de células viáveis que caracteriza produto probiótico e foi aceita sensorialmente.
\end{abstract}

PALAVRAS-CHAVE: EXTRATO DE SOJA; BEBIDA FERMENTADA; MEL.

* Bacharelandas em Química de Alimentos, Centro de Ciências Químicas, Farmacêuticas e de Alimentos, Universidade Federal de Pelotas, (UFPel), Pelotas, RS, Brasil (e-mail: manoelamarin@hotmail.com; nathi_madruga@hotmail.com).

** Doutora em Tecnologia de Alimentos, Professora, Centro de Ciências Químicas, Farmacêuticas e de Alimentos, UFPel, Pelotas, RS, Brasil (e-mail: rosane.rodrigues@ufpel.tche.br).

*** Doutora em Ciência e Tecnologia Agroindustrial, Professora, Centro de Ciências Químicas, Farmacêuticas e de Alimentos, UFPel, Pelotas, RS, Brasil (e-mail: miriangalvao@gmail.com). 


\section{INTRODUÇÃo}

Os consumidores têm procurado, cada vez mais, obter informações a respeito dos alimentos funcionais, tentando mudar seus hábitos alimentares tendo em vista à melhoria na saúde. Esse comportamento contribui para a popularização dos produtos com alegações à saúde, incentiva as indústrias na pesquisa de novos ingredientes, possibilita a inovação e o desenvolvimento de novos produtos, e expande os nichos de mercado (MATSUBARA, 2001; PRATES e MATEUS, 2002; FRANCO, 2006; FUCHS, 2006; MACHADO, 2007; SILVA, CARRÃO-PANIZZI e PRUDÊNCIO, 2009).

No contexto dos alimentos com alegações funcionais destacam-se a soja e seus derivados. Trata-se de leguminosa rica em proteínas, vitaminas, minerais, ácidos graxos poli-insaturados, fibras e oligossacarídeos com potencial prebiótico, como rafinose e estaquiose. Além disso, contêm outros compostos cujos benefícios à saúde são comprovados, como saponinas, lecitinas e isoflavonas (FUCHS et al., 2005, SILVA, CARRÃO-PANIZZI e PRUDÊNCIO, 2009). Estudos têm mostrado que o consumo regular de soja pode contribuir para a redução do risco da ocorrência de algumas enfermidades como as cardiovasculares, alguns tipos de câncer, osteoporose e sintomas da menopausa (HAN et al., 2002; KEMPKA et al., 2008; RODRIGUES e MORETTI, 2008; SILVA, CARRÃO-PANIZZI e PRUDÊNCIO, 2009).

Apesar do potencial nutritivo e funcional da soja, o grão e seus derivados ainda são pouco utilizados na dieta alimentar humana. Isso se deve principalmente ao aspecto sensorial considerado indesejável pelo consumidor. A presença de compostos voláteis com baixa massa molecular e dos oligossacarídeos rafinose e estaquiose são os fatores responsáveis, respectivamente, pelo sabor de feijão "cru" e pelos desconfortos abdominais e flatulência, principais envolvidos na baixa aceitação da soja (RODRIGUES, 2003; BEHRENS e SILVA, 2004; RODRIGUES e MORETTI, 2008; VIANA, BUENO e GÓES-FAVONI, 2011).

Dentre os produtos elaborados a partir da soja, o extrato de soja tem sido bastante utilizado para o consumo direto e na composição de outros produtos a exemplo das bebidas saborizadas (SILVESTRONI et al., 2002; LÓPEZ, 2003; RODRIGUES, 2003). Visando tornar o extrato de soja cada vez mais atrativo ao consumidor, tecnologias têm sido empregadas para melhorar as suas características sensoriais e nutricionais (BARBOSA, 2007; BRANCO et al., 2007; BREN, SANTOS e ALMEIDA, 2010).

A fermentação com culturas láticas representa uma das alternativas tecnológicas de transformação do extrato de soja, o qual tem se mostrado substrato adequado para o crescimento e atividade dessas bactérias devido aos oligossacarídeos, aminoácidos e peptídeos presentes no grão que estimulam o crescimento microbiano (HAULY, FUCHS e PRUDENCIO-FERREIRA, 2005; MACHADO, 2007). A adição de culturas láticas probióticas ao extrato de soja permite obter bebida fermentada, cujas propriedades sensoriais se assemelham ao iogurte tradicional; mascara o sabor característico do grão; diminui os oligossacarídeos não digeríveis (HAULY, FUCHS e PRUDENCIOFERREIRA, 2005; KOMATSU, BURITI e SAAD, 2008; PEREIRA et al., 2009) e confere os benefícios fisiológicos associados a esse grupo de micro-organismos (HELLER, 2001; FUCHS et al., 2005; HAULY, FUCHS e PRUDENCIO-FERREIRA, 2005; PEREIRA et al., 2009; BREN, SANTOS e ALMEIDA, 2010). Segundo a RDC $n^{\circ}$ 02/2002, da ANVISA, esses micro-organismos vivos são capazes de melhorar o equilíbrio microbiano intestinal, produzindo efeitos benéficos à saúde do indivíduo (BRASIL, 2002).

A incorporação de outros ingredientes ao extrato de soja fermentado com probióticos deve ser investigada a fim de melhorar as propriedades tecnológicas e funcionais do produto.

A utilização de lactossoro na elaboração de bebidas em associação com a soja constitui alternativa viável de aproveitamento desse produto secundário, que apresenta excelente valor nutritivo e potencialidade de efeitos funcionais fisiológicos, com destaque às proteínas e ácidos 
graxos (ALMEIDA, BONASSI e ROÇA, 2001; KEMPKA et al., 2008).

Prebióticos, a exemplo dos fruto-oligossacarídeos (FOS), também apresentam características interessantes para uso em bebidas devido seu sabor doce, semelhante ao da sacarose (YUN, 1996; SIQUEIRA, KOVALTCHUK e SILVEIRA, 2008) e efeitos benéficos à saúde pelo estímulo ao crescimento de bifidobactérias no trato digestivo (PASSOS e PARK, 2003).

O mel, alimento potencialmente funcional, exerce atividade prebiótica e pode ter como efeito a regulação do trânsito intestinal e da pressão arterial, redução do risco de alguns tipos de câncer e dos níveis de colesterol (ANJO, 2004). Além disso, pelas características de doçura e sabor peculiares, agrega sabor diferenciado à bebida e pode amenizar o sabor característico da soja (VIEIRA et al., 2011). A saborização do extrato pela adição de adoçantes, aromatizantes, sucos de frutas ou de aditivos melhora o aspecto sensorial e aumenta a aceitação do produto (RODRIGUES, 2003; FELBERG et al., 2004; BRANCO et al., 2007; PEREIRA et al., 2009; JAEKEL, RODRIGUES e SILVA, 2010).

Objetivou-se avaliar bebida funcional à base de extrato de soja, lactossoro e frutooligossacarídeo, fermentada com cultura probiótica e saborizada com mel.

\section{MATERIAL E MÉTODOS}

\subsection{MATERIAL}

Foram utilizados grãos de soja [Glicine max (L.) Merril] cultivar BRS-213 (EMBRAPA), fruto-oligossacarídeo (FOS) Beneo ${ }^{\circledR}$ P95 (Raftilose), soro de leite em pó (Danby-Cosulati, Pelotas, RS), açúcar (sacarose comercial), mel (adquirido no comércio de Pelotas, RS) e cultura probiótica de Lactobacillus acidophilus (LA - NCFM, Danisco Brasil Ltda., Cotia, SP), liofilizada e congelada.

\subsection{MÉTODOS}

\subsubsection{Preparo do extrato de soja e do lactossoro}

Obteve-se o extrato de soja por meio da seleção dos grãos, lavagem, maceração em água quente por 2 horas e trituração a quente em equipamento extrator SOJAMAC ${ }^{\circledR}$ MJ720 (FIZA, São Paulo, SP). Calculou-se a proporção soja/água para obtenção de extrato com aproximadamente $2 \%(\mathrm{~m} / \mathrm{m})$ de proteínas (BARBOSA, 2007; MACHADO, 2007).

Efetuou-se a reconstituição do soro de leite em pó a 12 \% em água potável para obtenção do lactossoro.

\subsubsection{Preparo do inóculo}

Preparou-se o inóculo no dia anterior ao uso, a partir da cultura liofilizada de LA-NCFM (Danisco Cultor) reativada em caldo MRS (De Mann, Rogosa e Sharpe - ACUMEDIA). Manteve-se o inóculo em estufa por 16 horas à temperatura de $37^{\circ} \mathrm{C}$.

\subsubsection{Elaboração da bebida probiótica à base de extrato de soja e lactossoro}

Preparou-se a bebida controle (não saborizada) pela mistura de $50 \%(\mathrm{~m} / \mathrm{m})$ de extrato de soja com $50 \%(\mathrm{~m} / \mathrm{m})$ de lactossoro, adicionados de $2,5 \%(\mathrm{~m} / \mathrm{m})$ de açúcar comercial e $5 \%(\mathrm{~m} / \mathrm{m})$ de FOS. A mistura foi aquecida $\left(85^{\circ} \mathrm{C}\right.$ ) e mantida por 20 minutos em banho termostatizado, sendo 
resfriada em banho de água e gelo até atingir a temperatura ideal de $42^{\circ} \mathrm{C}$ para adição do inóculo. Manteve-se a bebida fermentada em estufa a $42^{\circ} \mathrm{C}$ até que alcançasse o valor de $\mathrm{pH}$ próximo a 4,5 (MACHADO et al., 2011). Após a fermentação, a bebida foi resfriada até $20^{\circ} \mathrm{C}$ aproximadamente.

Para o preparo da bebida saborizada com mel efetuou-se o mesmo procedimento da bebida-controle, sendo adicionados $10 \%(\mathrm{~m} / \mathrm{m})$ de mel após a fermentação.

As bebidas fermentadas foram acondicionadas em recipientes de vidro com capacidade para $100 \mathrm{~mL}$ e armazenadas sob refrigeração $\left(5^{\circ} \mathrm{C}\right)$ até o momento das análises físico-químicas e sensoriais.

\subsubsection{Avaliações físico-químicas}

As bebidas probióticas saborizada com mel e não saborizada (controle) foram submetidas a análises físico-químicas de acordo com a AOAC (2003), sendo determinados, em triplicata: lipídios ( $n^{\circ}$ 90502); proteínas ( $n^{\circ}$ 99120); fibra bruta ( $n^{\circ}$ 98529/96052); acidez titulável (970.124); cinzas ( $n^{\circ}$ 94546) e sólidos totais ( $n^{\circ}$ 92523). Também foram determinados os sólidos solúveis, $\mathrm{pH}$, extrato seco, açúcares totais, redutores e não redutores, conforme o Instituto Adolfo Lutz (2008) e índice de sedimentação pela medida direta do volume de separação de fase em proveta graduada de $10 \mathrm{~mL}$, expresso em porcentagem (OLIVEIRA et al., 2002).

\subsubsection{Avaliação microbiológica}

Determinou-se a viabilidade celular 24 horas após o período de armazenamento sob refrigeração pela técnica de semeadura em profundidade, utilizando o ágar Man, Rogosa e Sharpe (MRS-Oxoid). As placas, em duplicata, foram incubadas a $37^{\circ} \mathrm{C}$ durante $72 \mathrm{~h}$ em jarras herméticas com emprego de geradores de anaerobiose (Anaerobac, Probac). As colônias foram contadas e o resultado expresso em logaritmo de unidades formadoras de colônias por mililitro (logUFC. $\mathrm{mL}^{-1}$ ).

\subsubsection{Avaliação sensorial}

Avaliou-se sensorialmente a bebida probiótica à base de soja e lactossoro saborizada com mel por método afetivo, utilizando teste de aceitação simultaneamente à escala hedônica estruturada de 7 pontos $(1$ = desgostei muito e 7 = gostei muito). Foram avaliados os atributos: cor, aroma, textura, sabor, acidez e impressão global das amostras (ABNT, 1993; DUTCOSKY, 2011). O teste ocorreu em cabines individuais, com luz branca, sendo as amostras servidas em copos plásticos de coloração branca em quantidades padronizadas (aproximadamente $10 \mathrm{~mL}$ ), refrigeradas a $10 \pm 2{ }^{\circ} \mathrm{C}$ e codificadas com números aleatório de três dígitos.

Realizou-se o teste na Universidade Federal de Pelotas com 70 julgadores não treinados, de ambos os sexos, com idades entre 18 e 50 anos, recrutados entre alunos, professores e funcionários da comunidade acadêmica.

\subsubsection{Análise estatística}

Os resultados das avaliações físico-químicas e sensoriais foram submetidos à análise de variância e teste de Tukey em nível de significância de $5 \%$, utilizando-se o programa Statistica 7.0 (STATSOFT, 2005).

\section{RESULTADOS E DISCUSSÃO}

Os valores de $\mathrm{pH}$ apresentados na Tabela 1 foram observados após seis horas a $42 \pm 1^{\circ} \mathrm{C}$, ao término da fermentação das bebidas. Estipulou-se o valor de referência em $4,5 \pm 0,2$, considerado 
adequado em bebidas à base de extrato de soja, quando ocorre a formação de gel e coagulação das proteínas no extrato. A produção de ácido láctico e concomitante redução de $\mathrm{pH}$ restringem o crescimento de micro-organismos patogênicos e putrefativos ácido-sensíveis (FUCHS et al., 2005).

Viana, Bueno e Góes-Favoni (2011), ao elaborarem bebida de soja fermentada do tipo iogurte, também obtiveram valores de $\mathrm{pH} 4,5$, porém com acidez de $0,33 \%$, inferior ao mensurado nas bebidas controle e com mel deste estudo. A acidez mostrou-se maior $(p<0,05)$ na bebida saborizada com mel. Segundo Macedo et al. (2008), o mel propicia maior produção de ácido por conter alto teor de carboidratos fermentescíveis.

A bebida saborizada diferiu do controle em relação ao teor de sólidos solúveis, apresentando valor significativamente maior devido à incorporação do mel. Esse adoçante natural elevou o teor de sólidos solúveis pela alta concentração de glicose e sacarose, que representam em média $85 \%$ dos carboidratos presentes (LENGLER, 2001).

\section{TABELA 1 - VALORES DE pH, ACIDEZ TITULÁVEL E SÓLIDOS SOLÚVEIS DE BEBIDA PROBIÓTICA À BASE DE EXTRATO DE SOJA, LACTOSSORO E FRUTO-OLIGOSSACARÍDEO SABORIZADA COM MEL E SEM SABOR (CONTROLE)}

\begin{tabular}{ccc}
\hline Determinação & \multicolumn{2}{c}{ Bebida } \\
& Controle & Com mel \\
\hline $\mathrm{pH}$ & 4,45 & 4,52 \\
Acidez titulável (\% ácido láctico) & $0,46^{\mathrm{a}}$ & $0,54^{\mathrm{b}}$ \\
Sólidos solúveis ( ${ }^{\circ}$ Brix) & $11,5^{\mathrm{a}}$ & $17,5^{\mathrm{b}}$ \\
Sedimentação em 24 h (\%) & $0,23 \pm 0,047^{\mathrm{b}}$ & $1,09 \pm 0,008^{\mathrm{a}}$ \\
Sedimentação em 48 h (\%) & $0,44 \pm 0,009^{\mathrm{b}}$ & $1,27 \pm 0,021^{\mathrm{a}}$ \\
\hline
\end{tabular}

Média de 3 repetições \pm desvio padrão.

Médias seguidas por letras distintas na mesma linha diferem entre si ao nível de $5 \%$ de significância pelo teste de Tukey $(p \leq 0,05)$.

Os valores encontrados para o índice de sedimentação, após 24 e 48 horas para a bebida com mel e o controle apresentaram variação entre 0,23 a 0,44 e 1,09 a 1,27 \%, respectivamente. A bebida com mel mostrou menor estabilidade física, mas a diferença na velocidade de separação de fases manteve-se em torno de 0,8 pontos percentuais após 24 e 48 horas em relação à bebida controle. A estabilidade física representa importante parâmetro sob o ponto de vista sensorial que, no caso de bebidas proteicas como a deste estudo, pode ser afetada pelo pH ácido da fermentação. Essa condição induz a agregação e precipitação das proteínas pela força iônica que interfere no grau de dissociação dos grupos funcionais dos aminoácidos, alterando a carga da proteína e sua solubilidade dentre outros fatores, como a constante dielétrica do solvente e a temperatura (RIBEIRO e SERAVALLI, 2004).

Na Tabela 2 estão expressos os resultados médios da composição proximal da bebida probiótica à base de soja saborizada ou não com mel.

As bebidas não diferiram em relação aos teores de lipídeos, fibras e proteínas, evidenciando que o percentual de mel adicionado como saborizante não modificou esses parâmetros. Contudo, ocorreu aumento no teor lipídico da bebida saborizada em razão do mel apresentar 1,87 mg de gordura por $100 \mathrm{~g}$ (VENTURINI, SARCINELLI e SILVA, 2007). A amostra sem mel evidenciou teor 
lipídico próximo a $2 \%$, valor proporcional à quantidade de grão utilizada para a elaboração da bebida.

O valor de proteínas encontrado não atingiu os $2 \%$ utilizados no extrato de soja elaborado inicialmente, indicando a possibilidade do seu consumo pelos micro-organismos. O Lactobacillus acidophilus da linhagem NCFM tem a característica de ser altamente auxotrófico, porém não apresenta a capacidade de síntese da maioria dos aminoácidos, vitaminas e cofatores. Essa deficiência é compensada pela presença de genes codificadores da via fermentativa e do transporte de proteínas (ALTERMANN et al., 2005).

\section{TABELA 2 - COMPOSIÇÃO PROXIMAL DE BEBIDA PROBIÓTICA À BASE DE EXTRATO DE SOJA, LACTOSSORO E FRUTO-OLIGOSSACARÍDEO SABORIZADA COM MEL E SEM SABOR (CONTROLE)}

\begin{tabular}{ccc}
\hline & \multicolumn{2}{c}{ Bebida } \\
Determinação (\%) & Controle & Com mel \\
\hline Lipídeos & $2,2 \pm 0,5^{\mathrm{a}}$ & $3,13 \pm 0,26^{\mathrm{a}}$ \\
Proteínas & $1,7 \pm 0,04^{\mathrm{a}}$ & $1,67 \pm 0,08^{\mathrm{a}}$ \\
Açúcar total & $5,53 \pm 0,07^{\mathrm{b}}$ & $11,03 \pm 0,19^{\mathrm{a}}$ \\
Açúcar redutor & $2,6 \pm 0,12^{\mathrm{b}}$ & $6,57 \pm 0,17^{\mathrm{a}}$ \\
Açúcar não redutor & $4,32 \pm 0,17^{\mathrm{a}}$ & $4,32 \pm 0,17^{\mathrm{a}}$ \\
Fibras & $0,3 \pm 0,12^{\mathrm{a}}$ & $0,25 \pm 0,00^{\mathrm{a}}$ \\
Cinzas & $0,13 \pm 0,04^{\mathrm{b}}$ & $0,54 \pm 0,004^{\mathrm{a}}$ \\
Extrato seco & $15,06 \pm 0,04^{\mathrm{b}}$ & $17,15 \pm 0,59^{\mathrm{a}}$ \\
\hline
\end{tabular}

Média de 3 repetições \pm desvio padrão. Médias seguidas por letras distintas na mesma linha diferem entre si ao nível de 5 \% de significância pelo teste de Tukey $(p \leq 0,05)$.

Os valores de proteína encontrados aproximaram-se dos verificados por Rodrigues e Moretti (2008) ao estudarem bebida de extrato de soja adicionado de polpa de pêssego (teor de $2,23 \%$ ). Os mesmos autores relataram que bebidas à base de soja disponíveis no mercado fornecem baixa quantidade de proteína de soja, entre 0,6 e 1,4 \%. Tal fato pode estar ligado às dificuldades tecnológicas encontradas em seu desenvolvimento, como em relação aos aspectos sensoriais negativos da soja, quando se trabalha com percentuais de extrato mais elevados. Desta forma, produtos com maior concentração de soja serão menos aceitos pelos consumidores.

O teor de cinzas foi significativamente $(p<0,05)$ maior na bebida saborizada, considerando que o mel apresenta em média 0,6 \% de minerais em sua composição. Da mesma forma, os teores de açúcares totais e redutores aumentaram na bebida com mel que apresenta em média $74 \%$ desses açúcares (SILVA et al., 2006; BERTOLDI et al., 2007).

\subsection{AVALIAÇÃO MICROBIOLÓGICA}

Os valores das contagens de células viáveis na bebida de soja probiótica e no controle são apresentados na Tabela 3. 


\section{TABELA 3 - CONTAGEM DE LACTOBACILOS ACIDÓFILOS EM BEBIDA PROBIÓTICA À BASE DE EXTRATO DE SOJA, LACTOSSORO E FRUTO-OLIGOSSACARÍDEO SABORIZADA COM MEL E SEM SABOR (CONTROLE)}

\begin{tabular}{lc}
\hline Bebida & Log UFC. $\mathrm{mL}^{-1}$ \\
\hline Com mel & 8,48 \\
Controle & 8,69 \\
\hline
\end{tabular}

A bebida adicionada de $10 \%(\mathrm{v} / \mathrm{v})$ de mel apresentou concentração menor de células viáveis de Lactobacillus acidophilus em relação ao controle, porém manteve-se de acordo com o padrão de no mínimo $10^{6} \mathrm{UFC} \cdot \mathrm{mL}^{-1}$ na contagem de células viáveis para produtos probióticos (VINDEROLA e REINHEIMER, 2000). Estudos similares, realizados por Curda e Plockova (1995), avaliaram o efeito de diferentes concentrações de mel (0, 1, 3, 5 e $10 \%)$ adicionadas em leite sobre o crescimento de $L$. acidophilus e cultura de bactérias mesófilas. Os méis receberam tratamentos diferentes, sendo um esterilizado a $121{ }^{\circ} \mathrm{C}$ por 15 minutos e o outro sem tratamento algum. Os resultados revelaram que L. acidophilus foi inibido em concentrações superiores a $5 \%$ de mel, independente do tratamento.

A menor concentração de células viáveis observada na bebida saborizada pode estar associada à atividade antimicrobiana do mel. Tal atividade deve-se a fatores físicos, como sua alta osmolaridade e acidez, e a fatores químicos relacionados com a presença de substâncias inibidoras, como o peróxido de hidrogênio, e substâncias voláteis, como os flavonoides e ácidos fenólicos (WAHDAN, 1998). Apesar disso, obteve-se contagem de células viáveis satisfatórias em ambas as bebidas, as quais apresentaram valores de contagem muito próximos.

\subsection{ANÁLISE SENSORIAL}

$\mathrm{Na}$ Tabela 4 são apresentadas as médias das notas obtidas para os atributos sensoriais de cor, aroma, textura, sabor, acidez e impressão global da bebida fermentada probiótica saborizada com mel.

\section{TABELA 4 - ACEITABILIDADE DE BEBIDA PROBIÓTICA À BASE DE EXTRATO DE SOJA, LACTOSSORO E FRUTO-OLIGOSSACARÍDEO SABORIZADA COM MEL}

\begin{tabular}{cc}
\hline Atributo & Média* $^{*}$ \\
\hline Cor & $4,97 \pm 1,38$ \\
Aroma & $4,88 \pm 1,63$ \\
Textura & $5,20 \pm 1,43$ \\
Sabor & $5,35 \pm 1,34$ \\
Acidez & $4,70 \pm 1,43$ \\
Impressão global & $5,25 \pm 1,18$ \\
\hline
\end{tabular}

NOTA: * Média de 70 julgadores \pm desvio padrão.

O sabor alcançou a maior média entre os atributos sensoriais avaliados, correspondendo ao termo "gostei ligeiramente" na escala hedônica. Esse resultado pode estar relacionado à 
fermentação que ameniza o sabor característico da soja, pois as culturas probióticas associadas ao extrato de soja podem diminuir os compostos voláteis presentes no grão que proporcionam sabor desagradável (FERRAGUT et al., 2009). Constatou-se que a adição de mel à bebida contribuiu para a aceitação do seu sabor. Machado et al. (2007) verificaram maior preferência para a bebida adoçada comparativamente àquela sem adição de açúcar. As altas concentrações de frutose e glicose presentes no mel mascaram o sabor da soja, minimizando o amargor do extrato (BARBOSA, 2007; VIEIRA et al., 2011). O mesmo foi verificado no estudo de Branco et al. (2007) sobre a aceitabilidade de bebida à base de extrato de soja com $25 \%$ de polpa de morango e $15 \%$ de sacarose que alcançou média de 6,47 ("gostei muito" e "gostei regularmente").

$\mathrm{Na}$ análise da textura, aproximadamente $84 \%$ dos julgadores aceitaram a consistência da bebida probiótica. A frutose e a glicose, por serem os constituintes principais do mel, proporcionaram maior cremosidade à bebida (BUCHARLES, 2007). O uso de $50 \%(\mathrm{~m} / \mathrm{m})$ de lactossoro na bebida também pode ter contribuído para a aceitação do atributo textura. Segundo Fuchs et al. (2005) para se obter bebida com textura semelhante ao iogurte torna-se necessária a suplementação com leite de vaca, soro ou proteínas do leite e açúcares (como lactose, frutose ou sacarose). Na pesquisa de Vieira et al. (2011), 26,92 \% dos julgadores atribuíram nota 6 (gostei ligeiramente) para a textura de bebida fermentada à base de soja com mel de abelha e $42,3 \%$ nota 8 (gostei muito) para a bebida adicionada de mel de engenho.

A acidez apresentou a menor média, recebendo nota 4 (nem gostei/nem desgostei) de $24,2 \%$ dos julgadores e nota 5 (gostei ligeiramente) de $25,7 \%$ deles. A acidez resultante do processo fermentativo foi de $0,54 \%$ de ácido lático, podendo ter influenciado a resposta dos julgadores considerando que a adição de culturas probióticas ao extrato produz ácidos orgânicos (KEMPKA et al., 2008).

O atributo aroma recebeu nota 5 (gostei ligeiramente) de $32,8 \%$ dos julgadores e a cor nota 6 (gostei moderadamente) de $31,4 \%$ dos participantes do teste.

A variabilidade na aceitação das bebidas pode ocorrer devido às diferenças culturais dos consumidores, das variedades de soja e do seu tipo de processamento, entre outros fatores (Figura 1).

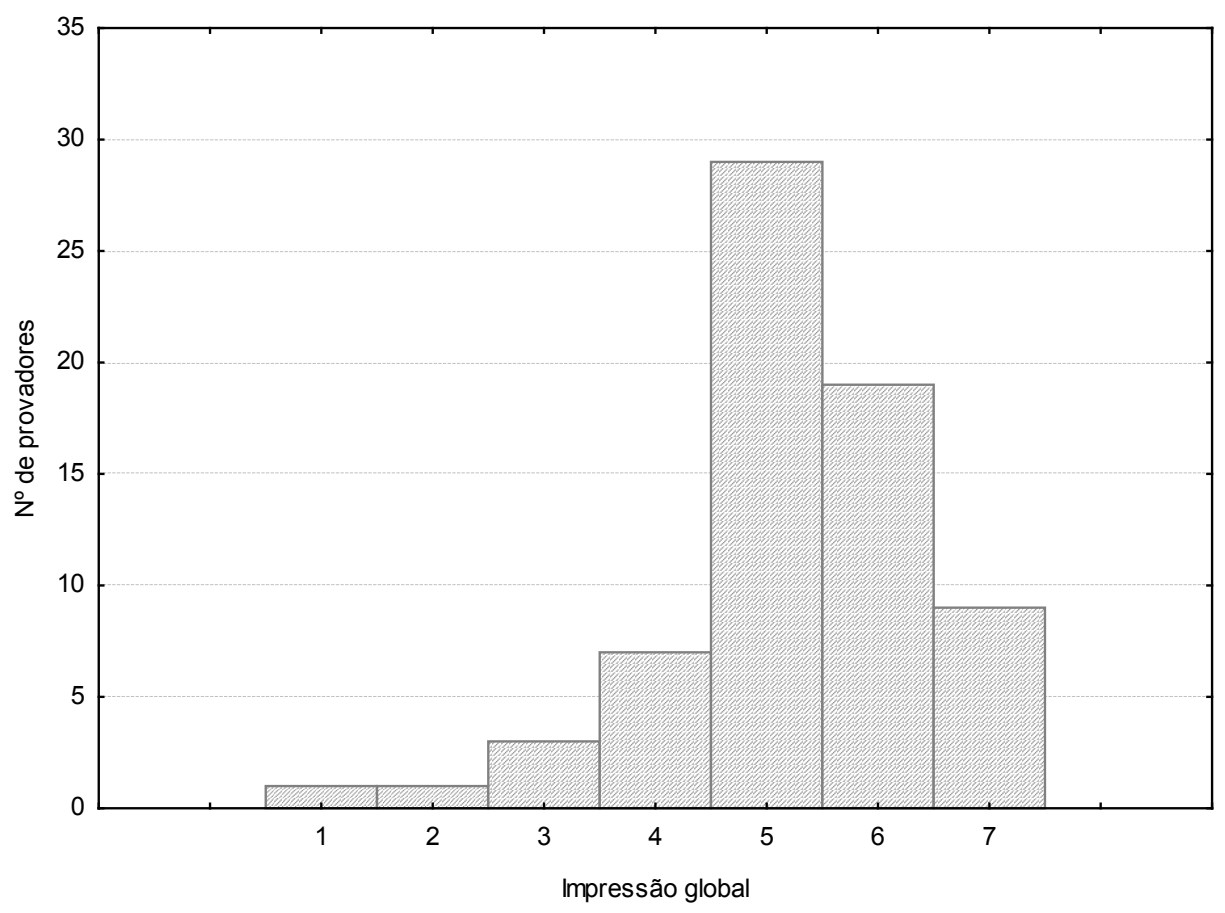

\footnotetext{
FIGURA 1 - FREQUÊNCIA DE NOTAS PARA IMPRESSÃO GLOBAL DE ACEITAÇÃO DE BEBIDA PROBIÓTICA À BASE DE EXTRATO DE SOJA, LACTOSSORO E FRUTO-OLIGOSSACARÍDEO SABORIZADA COM MEL
} 


\section{CONCLUSÃO}

A bebida desenvolvida à base de extrato de soja, lactossoro e fruto-oligossacarídeo, fermentada com cultura probiótica de Lactobacillus acidophilus e saborizada com mel apresentou parâmetros físico-químicos adequados, manteve-se de acordo com o padrão exigido pela legislação brasileira para contagem de número de células viáveis que caracteriza os produtos probióticos e foi aceita sensorialmente, com maior nota para o atributo sabor.

\section{ABSTRACT \\ PHYSICO-CHEMICAL AND SENSORIAL CHARACTERISTICS OF A PROBIOTIC BEVERAGE WITH SOY}

The aim of this study was to evaluate a functional beverage prepared with soybean extracts, whey and fructooligosaccharide (FOS), fermented with the probiotic Lactobacillus acidophilus (LA - NCFM) and flavored with honey. A control beverage (not flavored) was prepared by mixing $50 \%$ (w/w) of soybean extract with $50 \%$ $(\mathrm{w} / \mathrm{w})$ of whey, $2.5 \%(\mathrm{w} / \mathrm{w})$ of commercial sugar and $5 \%(\mathrm{w} / \mathrm{w})$ of FOS. After pasteurization $\left(85^{\circ} \mathrm{C} / 20 \mathrm{~min}\right)$ it was cooled and fermented with LA-NCFM at $42^{\circ} \mathrm{C}$ to $\mathrm{pH} 4.5$. The beverage flavored with honey was prepared through the same procedure and $10 \%(\mathrm{w} / \mathrm{w})$ of honey was added after fermentation. Lipids, proteins, fiber, acidity, ash, total solids, soluble solids, $\mathrm{pH}$, total reducing and nonreducing sugars, and sedimentation rate were determined in triplicate for both beverages. Cell viability was determined at 0,15 and 30 days after fermentation. The beverage flavored with honey was evaluated through affective sensory method using the acceptance test with a 7-point hedonic scale. The beverage containing soy extract, fructooligosaccharide and whey, fermented with probiotic, and flavored with honey, showed adequate physicochemical parameters, that were in accordance to the standard required by Brazilian law regarding the number of viable cells in probiotic product. The beverage had good sensory acceptance, with highest score for flavor attribute.

KEY-WORDS: EXTRACT OF SOYBEANS; FERMENTED BEVERAGE; HONEY.

\section{REFERÊNCIAS}

1 Associação Brasileira de Normas Técnicas (ABNT). NBR 12806: análise sensorial dos alimentos e bebidas. Rio de Janeiro, 1993. 8 p.

2 ALMEIDA, K.E.; BONASSI, I.A.; ROÇA, R.O. Características físicas e químicas de bebidas lácteas fermentadas e preparadas com soro de queijo minas frescal. Ciência e Tecnologia de Alimentos, São Paulo, v.2, n.2, p.187-192, 2001.

3 ALTERMANN, E.; RUSSEL, W.M.; AZCARATE-PERIL, M.A.; BARRANGOU, R.; BUCK, B.L.; McAULIFFE, O.; SOUTHER, N.; DOBSON, A.; DUONG, T.; CALLANAN, M.; LICK, S.; HAMRICK, A.; CANO, R.; KLAENHAMER, T.R. Complete genome sequence of the probiotic lactic acid bacterium Lactobacillus acidophilus NCFM. Proceedings of the National Academy Science, v.102, n.11, p.3906-3912, 2005.

4 ANJO, D.F.C. Alimentos funcionais em angiologia e cirurgia vascular. Jornal Vascular Brasileiro, v.3, n.2, p.145-154, 2004.

5 Association of Official Analitycal Chemists (AOAC). Official methods of analysis of the AOAC International. $17^{\text {th }}$ ed. Washington, 2003.

6 BARBOSA, E.G. Prevalência de bactéria probiótica $L$. acidophilus - NCFM em extrato de soja fermentado e saborizado com sacarose e polpa de pêssego. 2007. 58 f. Dissertação (Mestrado em Ciência e Tecnologia Agroindustrial) - Faculdade de Agronomia Eliseu Maciel, Universidade Federal de Pelotas, Pelotas, 2007.

7 BEHRENS, J.H.; SILVA, M.A.A.P. Atitude do consumidor em relação à soja e produtos derivados. Revista Ciência e Tecnologia de Alimentos, v.24, n.3, p.431-439, 2004.

8 BERTOLDI, F.C.; REIS, V.D.A.; GONZAGA, L.V.; CONGRO, C.R. Caracterização físico-química e sensorial de amostras de mel de abelhas africanizadas (Apis mellifera L.) produzidas no pantanal. Evidência, Joaçaba, v.7, n.1, p.63-74, 2007.

9 BRANCO, I.G.; TEIXARA, A.M.; RIGO, M.; BEZERRA, J.R.M.V; COUTINHO, M.R.; ARGANDOÑA, E.J.S.; BASTOS, R.G. Avaliação da aceitabilidade sensorial de uma bebida à base de extrato hidrossolúvel de soja, polpa de morango e sacarose. Revista Ciências Exatas e Naturais, v.9, n.1, p.129-141, 2007. 
10 BRASIL. Ministério da Saúde. Agência Nacional de Vigilância Sanitária. Resolução RDC $n^{\circ} 2$, de 07 de janeiro de 2002. Regulamento técnico de substâncias bioativas e probióticos isolados com alegação de propriedades funcional e ou de saúde. Diário Oficial [da] República Federativa do Brasil, Brasília, DF, 09 de janeiro de 2002. p. 191.

11 BREN, E.; SANTOS, L.; ALMEIDA, J.V.P. Desenvolvimento de bebida probiótica a partir de extrato solúvel de soja. Revista Brasileira de Tecnologia Agroindustrial, Ponta Grossa, v.4, n.1, p.100-108, 2010.

12 BUCHARLES, P.; MAURICIO, A.A.; SOUZA, F.C.; MARCILIO, R.; CARDELLO, H.M.A.B. Estudo do perfil sensorial da bebida de soja sabor chocolate In: ENCONTRO INTERNACIONAL DE PRODUÇÃO CIENTÍFICA CESUMAR, 5., Maringá, 2007. Anais ... Maringá: CESUMAR, 2007.

13 CURDA, L.; PLOCKOVA, M. Impedance measurement of growth of lactic acid bacteria in dairy cultures with honey addition. International Dairy Journal, v.5, n.7, p. 727-733, 1995.

14 DUTCOSKY, S.D. Análise sensorial de alimentos. 3 ed. Curitiba: Champagnat, 2011. 426 p.

15 FELBERG, I.; DELIZA, R.; GONÇALVES, E.B.; ANTONIASSI, R.; FREITAS, S.C.; CABRAL, L.C. Bebida mista de extrato de soja integral e castanha-do-Brasil: caracterização físico-química, nutricional e aceitabilidade do consumidor. Alimentos e Nutrição, Araraquara, v.15, n.2, p.163-174, 2004.

16 FERRAGUT, V.; CRUZ, N.S.; TRUJILLO, A.; GUAMIS, B.; CAPELLAS, M. Physical characteristics during storage of soy yogurt made from ultra-high pressure homogenized soymilk. Journal of Food Engineering, v.92, p.63-69, 2009.

17 FRANCO, R.C. Análise comparativa de legislações referentes aos alimentos funcionais. 2006.167 f. Dissertação (Mestrado em Nutrição Humana Aplicada) - Faculdade de Ciências Farmacêuticas, Universidade de São Paulo, São Paulo, 2006.

18 FUCHS, R.H.B. Utilização de Lactobacillus casei e cultura iniciadora na obtenção de iogurte suplementado com inulina e oligofrutose. Boletim do CEPPA, Curitiba, v.24, n.1, p 83-98, 2006.

19 FUCHS, R.H.B.; BORSATO, D.; BONA E.; HAULY M.C.O. logurte de soja suplementado com oligofrutose e inulina. Revista Ciência e Tecnologia de Alimentos, Campinas, v.25, n.1, p.175-181, 2005.

20 HAN, K.K.; SOARES, J.M. Jr.; HAIDAR, M.A.; GIRÃO, M.J.B.C.; NUNES, M.G.; LIMA, G.R; BARACAT, E.C. Efeitos dos fitoestrogênios sobre alguns parâmetros clínicos e laboratoriais no climatério. Revista Brasileira de Ginecologia e Obstetrícia, v.24, n.8, p.547-552. 2002

21 HAULY, M.C.O.; FUCHS, R.H.B.; PRUDENCIO-FERREIRA, S.H. Suplementação de iogurte de soja com frutooligossacarídeos: características probióticas e aceitabilidade. Revista de Nutrição, v.8, n.5, p.613-622, 2005.

22 HELLER, K.J. Probiotic bacteria in fermented foods: product characteristics and starter organisms. American Journal of Clinical Nutrition, v.73, p.374-379, 2001

23 Instituto Adolfo Lutz. Métodos químicos e físicos para análise de alimentos. 4. ed. São Paulo, 2008.1020 p.

24 JAEKEL, L.Z.; RODRIGUES, R. da S.; SILVA, A.P. Avaliação físico-química e sensorial de bebidas com diferentes proporções de extratos de soja e arroz. Ciência e Tecnologia de Alimentos, Campinas, v.30 n.2, p.342-348, 2010.

25 KEMPKA, A.P.; KRÜGER, L.; VALDUGA, E.; Di LUCCIO, M.; TREICHEL, H.; CANSIAN, R.; OLIVEIRA, D. Formulação de bebida láctea fermentada sabor pêssego utilizando substratos alternativos e cultura probiótica. Revista Ciência e Tecnologia de Alimentos, Campinas, v.28, p.170-177, 2008.

26 KOMATSU, T.R.; BURITI, F.C.A.; SAAD, S.M.I. Inovação, persistência e criatividade superando barreiras no desenvolvimento de alimentos probióticos. Revista Brasileira de Ciências Farmacêuticas, v.44, p.329-347, 2008.

27 LENGLER, S. Inspeção de controle da qualidade do mel. Santa Maria, RS: Universidade Federal de Santa Maria/ Departamento de Zootecnia, 2001. v.1.

28 LIU, K. Soybeans: chemistry, technology and utilization. New York: Chapman \& Hall, 1999. 532 p.

29 LÓPEZ, R. Apelo saudável potencializa mercado de bebidas à base de soja. Engarrafador Moderno, n.111, p.18-22, 2003.

30 MACEDO, L.N.; LUCHESE, R.H.; GUERRA, A.F.; BARBOSA, C.G. Efeito prebiótico do mel sobre o crescimento e viabilidade de Bifidobacterium spp. e Lactobacillus spp. em leite. Revista Ciência e Tecnologia de Alimentos, v.28, n.4, p.935-942, 2008. 
31 MACHADO, M.R.G. Bebida de soja fermentada com Lactobacillus acidophilus: viabilidade celular, avaliação sensorial, armazenamento e resposta funcional. 2007. 101 f. Tese (Doutorado em Ciência e Tecnologia Agroindustrial) Faculdade de Agronomia Eliseu Maciel, Universidade Federal de Pelotas, Pelotas, 2007.

32 MACHADO, M.R.G.; RODRIGUES, R. da S.; BARBOSA, E.G.; SCHONS, P.F.; PÓLVORA, M.S.; PRATES, D. da F.; GULARTE, M.A.; ROMBALDI, C.V. Preferência de bebida de soja probiótica fermentada. In: CONGRESO ARGENTINO DE CIENCIA Y TECNOLOGÍA DE ALIMENTOS, 11., SIMPÓSIO INTERNACIONAL DE NUEVAS TECNOLOGIAS, 2., Buenos Aires, 2007. Anais ... Buenos Aires: AATA, 2007, v.1.

33 MACHADO, M.R.G.; RODRIGUES, R. da S.; REISSIG, G.N.; SOUZA, M.M. Bebida potencialmente simbiótica à base de soja, lactossoro e frutooligossacarideo. In: CONGRESO ARGENTINO CYTAL, 13., 2011, Buenos Aires, 2011. Anais ... Buenos Aires: AATA, 2011

34 MATSUBARA, S. Alimentos funcionais: uma tendência que abre perspectivas aos laticínios. Revista Indústria de Laticínios, São Paulo, v.6, n.34, p.10-18, 2001.

35 MAZZA, G. Alimentos funcionales: aspectos bioquimicos y de procesado. Zaragoza: Acribia, 1998. 457 p.

36 OLIVEIRA, M.N.; SODINI, I.; REMEUF, F.; TISSIER, J.P.; CORRIEU, G. Manufacture of fermented lactic beverages containing probiotic cultures. Journal of Food Science, v.67, n.6, p.2336-2341, 2002.

37 PASSOS, L.M.L.; PARK, Y.K. Fruto-oligossacarídeos: implicações na saúde humana e utilização em alimentos. Ciência Rural, Santa Maria, v.33, n.2, p.385-390, 2003.

38 PEREIRA, M.O; BAMPI; M.; RODRIGUES, F.T.; SANTA, O.R.D.; SANTA, H.S.D.; RIGO, M. Elaboração de uma bebida probiótica fermentada a partir de extrato hidrossolúvel de soja com sabor de frutas. Revista do Setor de Ciências Agrárias e Ambientais, Guarapuava, v.5, n.3, p.475-487, 2009.

39 PRATES, J.A.M.; MATEUS, C.M.R. Componentes com atividade fisiológica dos alimentos de origem animal. Revista Portuguesa de Ciências Veterinárias, v.97, n.541, p.3-12, 2002.

40 RIBEIRO, E.P.; SERAVALLI, E.A.G. Química de alimentos. São Paulo: Edgard Blücher, 2004. 184 p.

41 RODRIGUES, R. da S. Caracterização de extratos de soja obtidos de grãos, farinha integral e isolado protéico visando a formulação e avaliação biológica (em coelhos) de bebida funcional à base de extrato de soja e polpa de pêssegos. 2003. 177 f. Tese (Doutorado em Tecnologia de Alimentos) - Faculdade de Engenharia de Alimentos, Universidade Estadual de Campinas, Campinas, 2003.

42 RODRIGUES, R. da S.; MORETTI, R.H. Caracterização físico-química de bebida proteica elaborada com extrato de soja e polpa de pêssego. Boletim do CEPPA, Curitiba, v.26, n.1, p.101-110, 2008.

43 SILVA, K.M.C.; LIMA, F.R.B.; SILVA, R.C.O.; SILVA, C.G.M. Soja (Glycine max): benefícios à saúde humana com melhor qualidade de vida. In: JORNADA DE ENSINO, PESQUISA E EXTENSÃO, 9., e SEMANA NACIONAL DE CIÊNCIA E TECNOLOGIA, 2009, Recife. Anais ... Recife: JAPEX, 2009. Disponível em: <http://www.eventosufrpe.com.br/jepex 2009/cd/resumos/ R0273-1.pdf>. Acesso em: 12 jan. 2012.

44 SILVA, J.B. da; CARRÃO-PANIZZI, M.C.; PRUDÊNCIO, S.H. Chemical and physical composition of grain-type and foodtype soybean for food processing. Pesquisa Agropecuária Brasileira, v.44, p.777-784, 2009.

45 SILVA, R.A.; MAIA, G.A.; SOUSA, P.H.M.; COSTA, J.M.C. Composição e propriedades terapêuticas do mel de abelha. Alimentos e Nutrição, v.17, n.1, p.113-120, 2006.

46 SILVESTRONI, A.; CONNES, C.; SESMA, F.; GIORI, G.S.; PIARD, J-C. Characterization of the mel Alocus for a-galactosidade in Lactobacillus plantarum. Applied and Environmental Microbiology, v.68, n.11, p.5464-5471, 2002.

47 SIQUEIRA, C.R.; KOVALTCHUK, E.; SILVEIRA, F.J. Frutooligossacarideos: uma revisão sobre propriedades funcionais, efeito na saúde humana e importância na indústria de alimentos. In: SEMANA DE TECNOLOGIA EM ALIMENTOS, 6. Ponta Grossa, 2008. Anais... Ponta Grossa: STA, 2008. v. 2.

48 STATSOFT, Inc. Statistica for Windows: computer program manual. Tulsa, OK, 2005.

49 VENTURINI, K.S.; SARCINELLI, M.F.; SILVA, L.C. da. Características do mel. Vitória: UFES, 2007.8 p. (Boletim Técnico do Programa Institucional de Extensão da Universidade Federal do Espírito Santo, 01107).

50 VIANA, A.; BUENO, F.R.; GÓES-FAVONI, S.P. Bebida fermentada de soja tipo iogurte: formulação e aceitabilidade. Revista Alimentus, v.1, p.7-16, 2011.

51 VIEIRA, D.M.; LIMA, S.E.R.; ALMEIDA, M.C.B.M.; SILVA, A.L; CHINELATE, G.C.B. Bebida fermentada à base de soja sabor mel: avaliação sensorial. In: SEMANA ACADÊMICA DA ENGENHARIA DE ALIMENTOS DE POMBAL, 1., 2011, Campina Grande. Anais ... Campina Grande: SAEAP, 2011. Disponível em:<http://www.gvaa.com.br/revista/ index.php/ CVADS/article/view/954/862>. Acesso em: 15 jan. 2012 
52 VINDEROLA, C.G.; REINHEIMER, J.A. Enumeration of Lactobacillus casei in the presence of $L$. acidophilus, bifidobacteria and lactic starter bacteria in fermented dairy products. International Dairy Journal, Amsterdam, v.10, n.4, p.271-275, 2000

53 WAHDAN, H. A. L. Causes of the antimicrobial activity of honey. Infection, v.26, n.1, p.26-31,1998.

54 YUN, J.W. Fructooligosaccharides - occurrence, preparation and applications. Enzymes and Microbial Technology, Kyungbug, v.19, n.2, p.107-117, 1996. 